\title{
IMPLICATION OF PARTIAL REPLACEMENT OF CEMENT WITH FA AND SAND BY GBS ON SETTING TIME AND WORKABILITY OF MORTAR
}

\author{
Sunil N Manjunath ${ }^{1}$, P V Sivapullaiah ${ }^{2}$, M Prasanna Kumar ${ }^{3}$ \\ ${ }^{I}$ M.Tech Student, Department of Civil Engineering, Manipal Institute of Technology, Manipal, Karnataka, India- \\ 576104, sunilnm09@gmail.com \\ ${ }^{2}$ Professor, Department of Civil Engineering, Indian Institute of Science, CV Raman Road, Yeshwanthpura, \\ Bengaluru, Karnataka, India-560012, siva@civil.iisc.ernet.in \\ ${ }^{3}$ Asst. Professor, Department of Civil Engineering, Manipal Institute of Technology, Manipal, Karnataka, India- \\ 576104,prasannakumar18186@gmail.com
}

\begin{abstract}
Fly Ash (FA) and Ground Blast Furnace Slag (GBS) are by-products obtained from the burning of coal in the thermal power plants and blast-furnace used to produce iron respectively. With a view to preserve natural materials like river sand and high energy consuming cement efforts are made to explore the possibility of replacing them with alternate materials including the industrial solid waste materials in the production mortar and concrete. It is in this context the setting time of FA and the workability of mortar are examined with these replacements. In the present investigation, $25 \%$ and $50 \%$ of Cement (C) is replaced by FA; and 25\%, 50\%, 75\% and 100\% of Sand (S) by GBS. Normal consistency and setting time increased with increasing replacement of cement with fly ash. However, the addition of $2 \%$ Calcium Chloride reduced the setting time of all pastes. Also, the results indicated that cement with upto 50\% of FA can be considered without seriously jeopardizing the setting time. The workability test on 1:3 mortar on all combinations were performed to get a flow value of $110+5$ as per IS $2250-1981$. To enhance the workability and consequently increase their strength $2 \%$ of super plasticizer has been incorporated. The water cement ratio increased with increase in replacement of sand by GBS. The replacement by FA upto 50\% did not reduce the water cement ratio of normal cement mortar. Also, workability tests on mortar samples have shown that, GBS can be used up to $50 \%$ of sand.
\end{abstract}

Keywords: Cement, FA, GBS, mortar, natural sand, replacements. $* * *$

\section{INTRODUCTION}

Cement manufacturing is highly energy and emissions intensive because of the extreme heat required to produce it. Producing a ton of cement requires 4.7 million BTU of energy, equivalent to about 400 pounds of coal, and generates nearly a ton of $\mathrm{CO}_{2}$. Given its high emissions and critical importance to society, cement is an obvious place to look to reduce greenhouse gas emissions. Sand is a naturally occurring granular material composed of finely divided rock and mineral particles. The composition of sand is highly variable, depending on the local rock sources and conditions. The construction industry demands only specific type of sand, for making mortar and concrete. This has lead to a huge demand and degradation of natural sources. Therefore, finding of alternative ways to meet the growing demand is of high priority in modern times. In order to achieve reduced environmental pollution and impact use of by-products to replace cement by Fly Ash (FA) and sand by Granulated Blast furnace Slag (GBS) has been proposed in this research. Radwan et al (2012) in their research paper had worked on substitution of Portland cement(C) pastes by GGBS. Priyanka et al (2013) experimental program studied the effect of replacement of natural sand by manufactured sand on the properties of cement mortar. Swaroop et al (2013) studied on the durability properties of concrete with the replacement of cement by Fly Ash and GGBS. Essam et al (2013) carried out a research work on Effect of calcium chloride on the hydration characteristics of ground clay bricks cement pastes. Marthong et al. (2012) conducted a research on effect on use of fly ash as an additive on concrete properties. Isa et al. (2006) in their research paper had studied the effect of replacement of sand by GBS and coal bottom ash in concrete strength and durability. These earlier researches have shown that of GBS and FA, in mortar and concrete can be used as a substitute material for sand and cement respectively. Based on the review, research has been carried out on evaluating normal consistency, initial and final setting time, and with effect on flow characteristics on substituting FA and GBS in place of cement and natural sand respectively.

\section{RESEARCH SIGNIFICANCE}

The objectives of the research are to study effect of FA on cement and GBS on sand. They are used in preparation of mortar with replacement materials. FA was substituted as $25 \%$ and $50 \%$ in place of cement with GBS substituted as 
$25 \%, 50 \%, 75 \%$ and $100 \%$ in place of sand. The cementitious material to sand ratio considered was $1: 3$ and the water cement ratio which gave a flow value of 110-115 using a flow table are being used to cast $50 \mathrm{~mm}$ cube specimens and cured under varying conditions for 28 days and tested for durability and compressive strength. For FA and GBS to be used as substitute materials, they have to satisfy certain desirable properties. The researches on cement mortar with both these materials used simultaneously are less; thus highlighting the necessity for experimentation.

\section{MATERIALS}

GBS was collected from KALYAN steel Industry $(4.75 \mathrm{~mm}$ to 75 micron) which is located in Karnataka. FA (Class F) was collected from Raichur Thermal Power Plant which is located in Raichur District in Karnataka. The calcium chloride used in this work was collected from locally available chemical laboratory. The type of calcium chloride used is in the form of pellets. In the present project the calcium chloride with more than $97 \%$ purity was used i.e., percentage of $\mathrm{CaCl}_{2}$ is more than $97 \%$. The Superplasticizer used in this research was collected from locally available concrete admixture store. The type of Superplasticizer used is chloride free, SNF polymer based. It was supplied as a brown solution which instantly disperses in water. It conformed to IS 9103:1999 specifications. OPC 53 Grade was used to prepare the mixes for the evaluation of all properties. There were no lumps formed when unpacked and was stored in air tight containers. It conformed to IS 12269:2013 specifications. The sand was collected from a nearby construction site $(4.75 \mathrm{~mm}$ to 75 micron). It was oven dried for 24 hours to remove moisture before evaluation of properties and preparation of mixes. It conformed to IS 650-1991 specifications. Potable water was used in all mixes. Salts and other organic impurities were absent. The results of Seive analysis and material properties of GBS and Sand are given in Table 1, Table 2 and Figure 1.

Table 1: Sieve analysis

\begin{tabular}{|l|l|l|l|l|}
\hline \multirow{3}{*}{ IS sieve } & \multicolumn{2}{|l|}{ Cumulative \% } & IS & IS \\
\cline { 2 - 5 } designation & wt. passing & $\mathbf{3 8 3 : 1 9 7 0}$ & $\mathbf{3 8 3 : 1 9 7 0}$ \\
\cline { 2 - 5 } & & & & \\
& SAND & GBS & ZONE 1 & ZONE 2 \\
\hline $4.75 \mathrm{~mm}$ & 98.4 & 99.076 & $90-100$ & $90-100$ \\
\hline $2.36 \mathrm{~mm}$ & 92.6 & 96.016 & $60-95$ & $75-100$ \\
\hline $1.18 \mathrm{~mm}$ & 73 & 82.186 & $30-70$ & $55-90$ \\
\hline $600 \mu$ & 39.4 & 31.510 & $15-34$ & $35-59$ \\
\hline $300 \mu$ & 20.4 & 10.406 & 5 to 20 & 8 to 30 \\
\hline $150 \mu$ & 0.8 & 1.488 & $0-10$ & $0-10$ \\
\hline
\end{tabular}

Table 2: Material Properties

\begin{tabular}{|l|l|l|l|}
\hline $\begin{array}{l}\text { Sr. } \\
\text { no. }\end{array}$ & Property & SAND & GBS \\
\hline 1. & Specific gravity & 2.62 & 2.25 \\
\hline 2. & Moisture & $.4 \%$ & $1 \%$ \\
\hline
\end{tabular}

\begin{tabular}{|l|l|l|l|} 
& absorption & & \\
\hline 3. & Fineness Modulus & 2.754 & 2.79 \\
\hline 4. & $\begin{array}{l}\text { Indian standard } \\
\text { zone }\end{array}$ & Zone 2 & $\begin{array}{l}\text { Fluctuates } \\
\text { between Zone } \\
1 \text { and Zone 2 }\end{array}$ \\
\hline 5. & Fines & $.8 \%$ & $1.49 \%$ \\
\hline
\end{tabular}

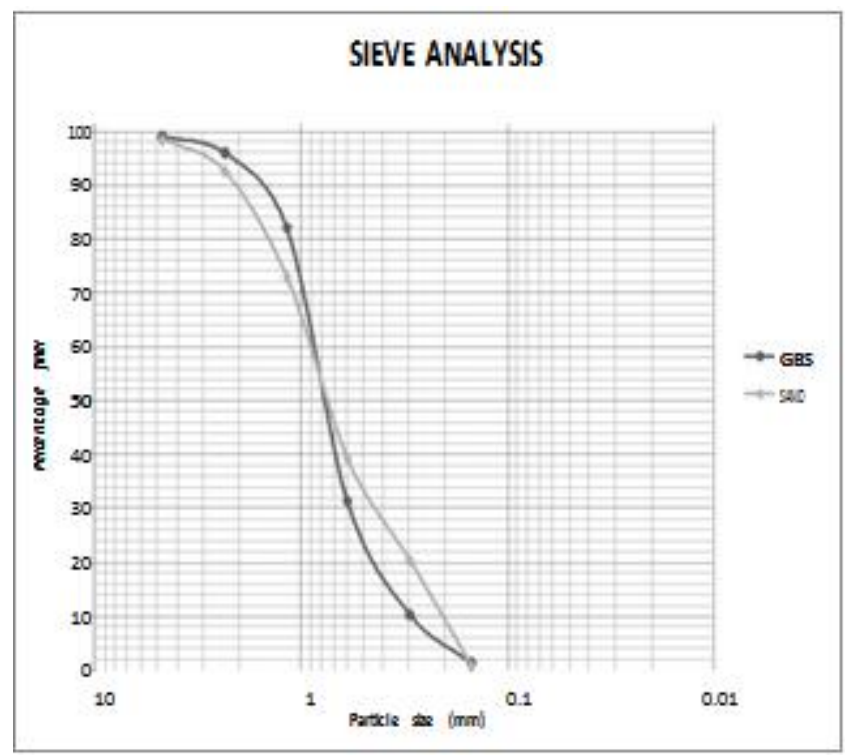

Fig 1: Sieve Analysis of GBS vs sand

\section{EXPERIMENTAL PROGRAM}

FA was added in percentages of 0,25 and 50 in place of cement and tested for normal consistency, initial and final setting time to check the suitability of usage in study of workability, durability and compressive strength. Calcium chloride was added $2 \%$ by mass of cementitious material. After evaluation of the above properties, the experiment work involves finding of water cement ratio, casting, curing and testing of specimens. Mortar specimens with proportion of 1:3 were evaluated to note down the water cement ratio for a flow value of 110 to 115 without appreciable segregation and bleeding. GBS was added in percentages of $0,25,50,75$ and 100 in place of sand to observe the changes in water cement ratio. The mortar ingredients were dry mixed first. Water and Superplasticizer were added and hand mixed, followed by mechanical mixing to get a good homogeneous mix. The sample was filled in two layers with 20 blows each layer in a mould placed on flow table. The mould was lifted and the sample was given 25 drops in 15 seconds. A Superplasticizer dosage of $2 \%$ by mass of cementitious material was added to all mortar samples.

\section{RESULTS AND DISCUSSIONS}

\subsection{Seive Analysis, Specific Gravity and Moisture}

\section{Absorption of GBS and Sand}

With reference to Table 1, Table 2 and Figure 1 the particle size Distribution is one of the significant parameter to classify and to inspect the strength variations. The use of 
GBS and sand in mortar needs a superplasticizer to achieve higher workability and compressive strength with reduced water- cement ratio. GBS unlike sand has glassy granular structure compared to spherical particles in sand. This leads to bleeding and segregation when the replacement levels with sand is appreciable. On the contrary, the structure of GBS improves compressive strength as the particles interlock with the cement matrix unlike the sprehical particles present in sand. Thus a balance needs to established between good workability and achieving higher compressive strength. The water absorption of GBS is lower than sand and hence it can be used as a substitute material for sand. The specific gravity of GBS being lower adds to more coverage of surface area in plastering etc., for the same amount of material compared to sand. Also the use of GGBS will improve the workablity due to introduction of finer cohesive material.

\subsection{Studies on Scanning Electron Microscopy}

\section{Images on Cement and FA}

Figure 2 and Figure 3 shows the SEM images obtained at $50 \mu \mathrm{m}$ on cement and FA samples respectively. As it is evident from the images, the particles in Cement are not spherical with predominant anomalous shapes. The reason behind this is milling of cement during its manufacture. FA comprises of several hollow to dense spheres, termed as cenospheres which have varying texture.

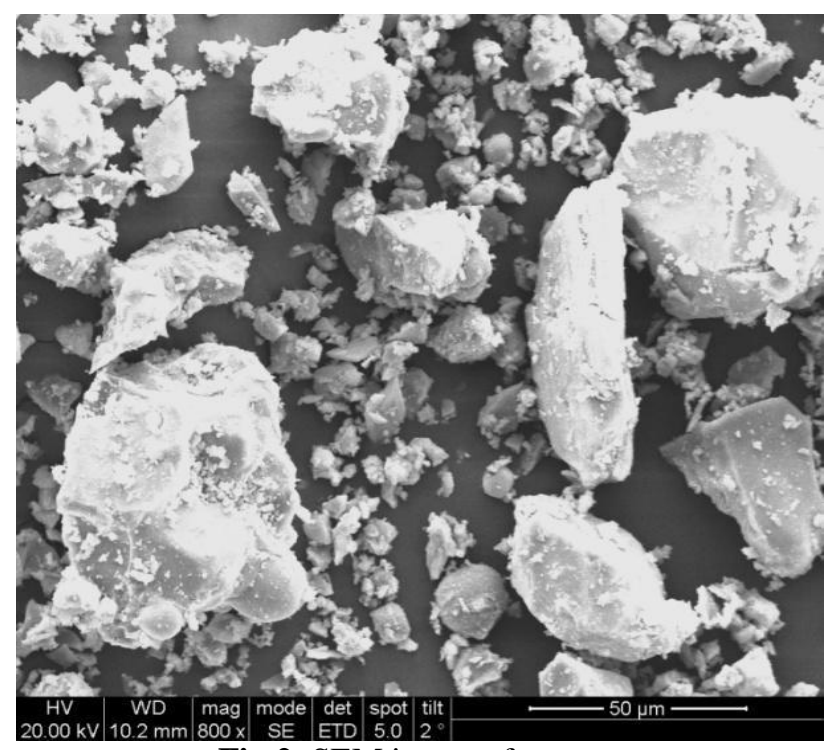

Fig 2: SEM image of cement

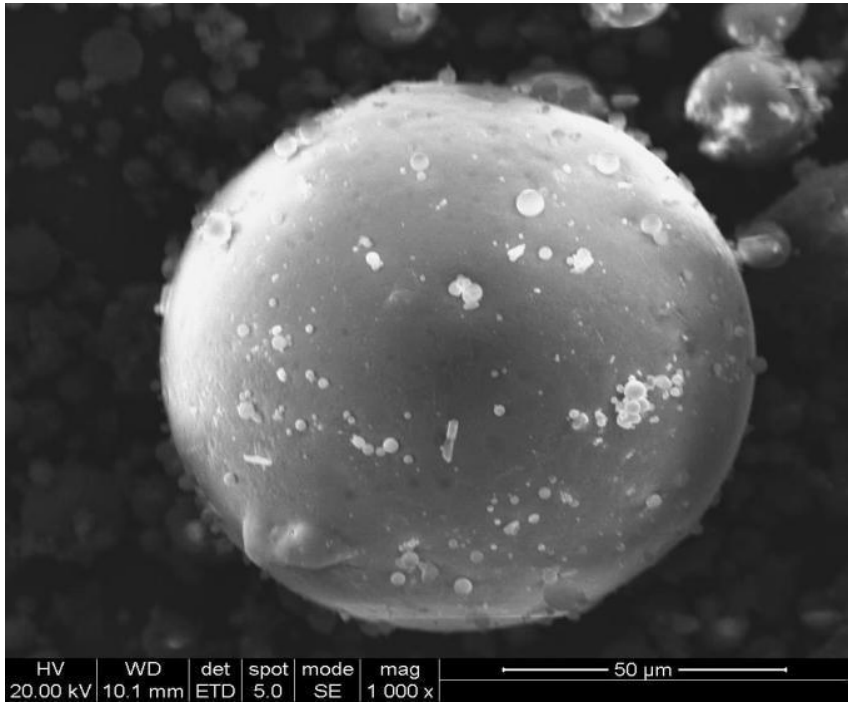

Fig 3: SEM image of FA

\subsection{Normal Consistency(NC), Initial and Final}

\section{Setting Time}

From the Table 3 and Figure 4 it is evident that the normal consistency value increases with higher percentages of replacement of Cement by FA. This can be accounted on the basis of fineness of material. Since FA is a finer material than cement, it requires more water to form a stiff and consistent paste compared to cement. From Table 4, Table 5, Figure 5 and Figure 6, it can be observed that initial setting and final setting time also increase with increase in FA content which is preferred as it allows hauling of cementitious mix for longer distances and time without getting set. The delay in final setting time of a $50 \%$ replaced cement paste is quite appreciable. The increase in set times is due to the presence of more silica content w.r.t calcium content in FA. The effect of $\mathrm{CaCl}_{2}$ on setting time was studied. $\mathrm{CaCl}_{2}$ was added $2 \%$ by mass of cementitious material. It appreciably affected both the initial and final setting time of cementitious paste. It reduced the initial and final setting time. This has applications were lower setting times are required for suitable constructional activities. Despite the use of $\mathrm{CaCl}_{2}$, longer set times are to be expected for cementitious pastes containing FA by mass. Values in () indicate the percentage increase in setting time in comparison with cement. The values in [] indicate the percentage decrease when $\mathrm{CaCl}_{2}$ was added to the pastes in comparison with primary pastes. 100C implies $100 \%$ Cement.

Table 3: Normal Consistency

\begin{tabular}{|l|l|l|}
\hline Sr.no. & PASTE TYPE & VALUE IN \% \\
\hline 1 & $100 \mathrm{C}$ & $29.14 \%$ \\
\hline 2 & $25 \mathrm{C}+75 \mathrm{FA}$ & $30.28 \%$ \\
\hline 3 & $50 \mathrm{C}+50 \mathrm{FA}$ & $31.43 \%$ \\
\hline
\end{tabular}


Table 4: Setting Time without $\mathbf{C a C l}_{2}$

\begin{tabular}{|c|c|c|c|}
\hline Sr. & $\begin{array}{l}\text { PASTE } \\
\text { TYPE } \\
\end{array}$ & $\begin{array}{l}\text { INITIAL } \\
\text { SETTING } \\
\text { TIME } \\
\text { (MINS) } \\
\end{array}$ & $\begin{array}{l}\text { FINAL } \\
\text { SETTING } \\
\text { TIME(MINS) }\end{array}$ \\
\hline 1 & $100 \mathrm{C}$ & 210 & 280 \\
\hline 2 & $25 \mathrm{C}+75 \mathrm{FA}$ & $225(7.14)$ & $325(16.07)$ \\
\hline 3 & $50 \mathrm{C}+50 \mathrm{FA}$ & $300(42.86)$ & $440(57.14)$ \\
\hline
\end{tabular}

Table 5: Setting Time with $\mathbf{C a C l}_{2}$

\begin{tabular}{|l|l|l|l|}
\hline $\begin{array}{l}\text { Sr. } \\
\text { no. }\end{array}$ & $\begin{array}{l}\text { PASTE } \\
\text { TYPE }\end{array}$ & $\begin{array}{c}\text { INITIAL } \\
\text { SETTING } \\
\text { TIME (MINS) }\end{array}$ & $\begin{array}{l}\text { FINAL } \\
\text { SETTING } \\
\text { TIME(MINS) }\end{array}$ \\
\hline 1 & $100 \mathrm{C}$ & $40[80.95]$ & $85[69.94]$ \\
\hline \multirow{2}{1}{} & $25 \mathrm{C}+75$ & & \\
\hline & FA & $50(25)[77.78]$ & $101(18.82)[68.92]$ \\
\hline 3 & $50 \mathrm{C}+50$ & & \\
\hline
\end{tabular}

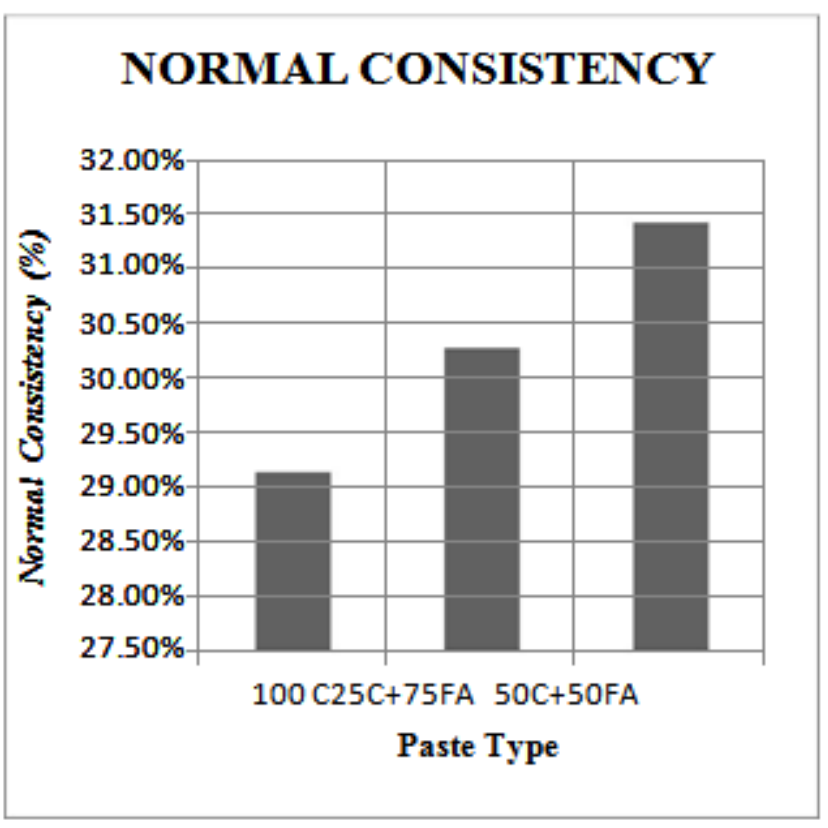

Fig 4: Variation in normal consistency value on replacing Cement by GGBS

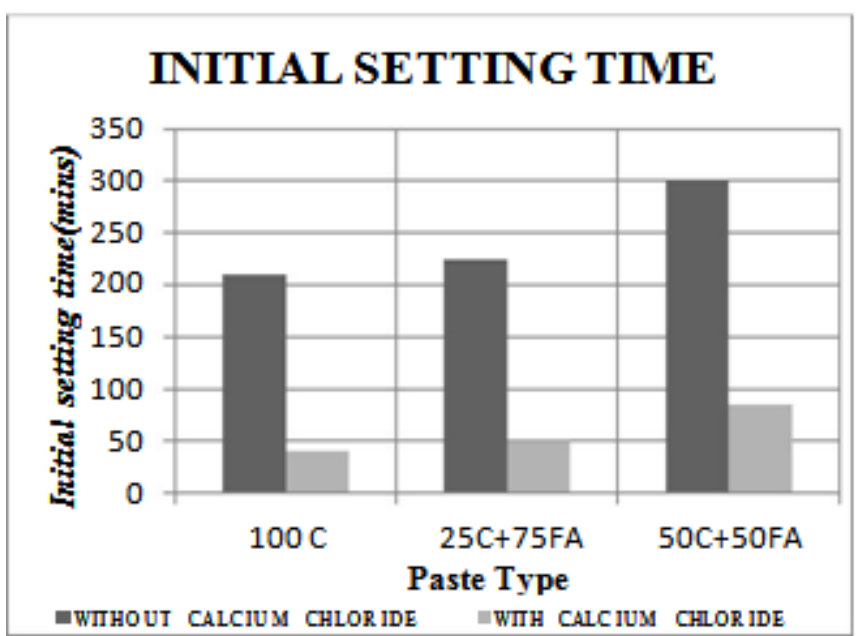

Fig 5: Variation in Initial setting time on usage of Calcium Chloride

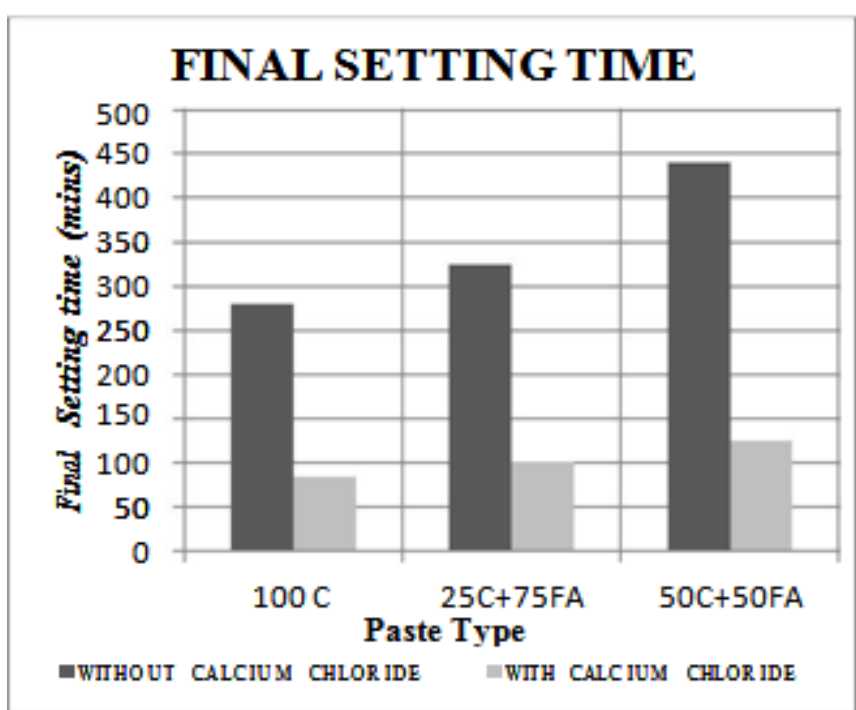

Fig 6: Variation in Final setting time on usage of Calcium Chloride

\subsection{Specific Gravity of Cement and FA}

The specific gravity of cement and FA was found to be 3.07 and 2.8 respectively. This indicates that lower quantity of FA material can be used for same constructional applications compared to that of cement. Thus there is a saving of material and also economy in large scale applications. It was also found that in finding the normal consistency, initial setting time and final setting time, the amount of material required to fill the Vicat mould reduced with higher replacements of cement with FA ranging from $20 \%$ to $50 \%$ with replacement levels from $25 \%$ to $100 \%$ respectively. As per IS code the amount of cement to be used is $400 \mathrm{gms}$ for finding normal consistency, initial and final setting time for a cement paste.

\subsection{Study on Flow Value}

The use of water alone leads to very high water cement ratio (>.9) along with segregation and bleeding. As evident from the sieve analysis, the use of GBS beyond $50 \%$ as a 
substitute material for Sand was not possible as it caused bleeding despite the use of Superplasticizer and cement replacements by FA. The use of mechanical mixer reduced the bleeding and segregation compared to manual mixing as binding of materials had to be achieved at lower water cement ratios with Superplasticizer dosage of $2 \%$. FA when substituted upto $25 \%$ initially increased the water cement ratio. This can be accounted on the fact that, the overall fineness of cementitious material had not increased appreciably upto $25 \%$ replacement levels. But it was observed that, the mortar sample achieved the flow value with no visible segregation or bleeding. At $50 \%$ replacements of cement by FA reflected same water cement ratios as that of only cement mortar samples. Thus, it is evident that despite, the increase in overall fineness of cementitious material, the water cement ratio did not reduce. Table 6 and Figure 7 show the results obtained. 100C and 100S imply $100 \%$ Cement and $100 \%$ Sand respectively.

Table 6: Flow Table Test Results

\begin{tabular}{|l|l|l|}
\hline Sr.no. & MORTAR TYPE & W/C RATIO \\
\hline 1. & $100 \mathrm{C}+100 \mathrm{~S}$ & 0.55 \\
\hline 2. & $100 \mathrm{C}+75 \mathrm{~S}+25 \mathrm{GBS}$ & 0.675 \\
\hline 3. & $100 \mathrm{C}+50 \mathrm{~S}+50 \mathrm{GBS}$ & 0.80 \\
\hline 4. & $75 \mathrm{C}+25 \mathrm{FA}+100 \mathrm{~S}$ & 0.575 \\
\hline 5. & $75 \mathrm{C}+25 \mathrm{FA}+75 \mathrm{~S}+25 \mathrm{GBS}$ & 0.70 \\
\hline 6. & $75 \mathrm{C}+25 \mathrm{FA}+50 \mathrm{~S}+50 \mathrm{GBS}$ & 0.90 \\
\hline 7. & $50 \mathrm{C}+50 \mathrm{FA}+100 \mathrm{~S}$ & 0.55 \\
\hline 8. & $50 \mathrm{C}+50 \mathrm{FA}+75 \mathrm{~S}+25 \mathrm{GBS}$ & 0.675 \\
\hline 9. & $50 \mathrm{C}+50 \mathrm{FA}+50 \mathrm{~S}+50 \mathrm{GBS}$ & 0.80 \\
\hline
\end{tabular}

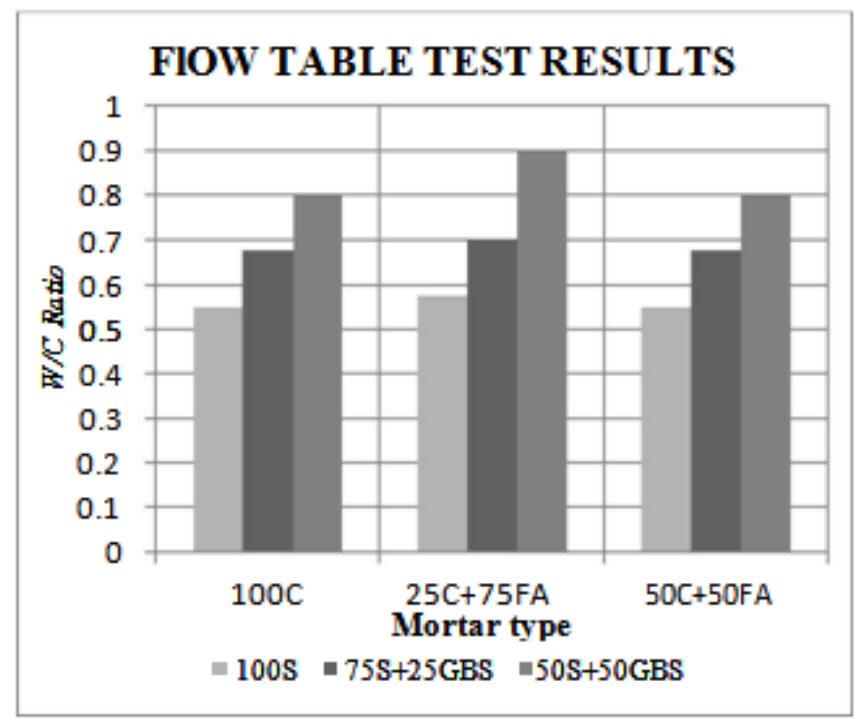

Fig 7: Variation in W/C Ratio on partial replacement of cement with FA and sand by GBS

\section{CONCLUSION}

1. The normal consistency increases with increasing replacement of cement by FA along with increase in initial and final setting time.

2. As FA contains relatively more silica, it will cause an increase in setting times but corresponding strength loss is to be expected because of lower calcium content.

3. Use of $\mathrm{CaCl}_{2}$ effectively reduces the set time of all pastes.

4. The replacement of sand by GBS increases water cement ratio of all mortar samples and with consequent effect on compressive strength.

5. The lower specific gravity of FA and GBS compared to cement and sand respectively will enhance to cover more area compared to same weight conventional cement sand mortar.

6. From the workability point of view GBS can be used upto $50 \%$ of sand.

7. The use of mechanical mixer has to be implemented to ensure proper uniformity and homogeneity of materials in the mortar samples.

\section{REFERENCES}

[1] A. M. Radwan, E. A. El-Alfi and R. M. Osman (2012). Characteristics of Portland cement pastes with high replacement of slag. ARPN Journal of Engineering and Applied Sciences, vol. 7, no.3.

[2] V. Supraja and M. Kanta Rao (2012). Experimental study on Geo-polymer concrete incorporating GGBS. IJECSCSE vol. 2, issue 2.

[3] Madheswaran C.K, Gnanasundar G and Gopalkrishnan. N (2013). Effect of molarity in Geopolymer concrete. IJCSE vol. 4, no 2.

[4] Priyanka A. Jadhav and Dilip K. Kulkarni (2013). Effect of replacement of natural sand by manufactured sand on properties of cement mortar. IJCSE, vol.3, no.3.

[5] Rafat Siddique and Rachid Bennacer (2012). Use of Iron and steel industry by-product (GGBS) in cement paste and mortar. Resources conservation and recycling 69: 29-34.

[6] A. H. L. Swaroop, K. Venkateswararao and P Kondandaramarao (2013) (2013). Durability studies on concrete with Fly ash and Ggbs. IJERA ISSN: 2248-9622 vol. 3, Issue 4: 285-289.

[7] Essam A. Kishar, Doaa A. Ahmed, Maha R. Mohammed, Rehab Noury (2013). Effect of calcium chloride on hydration characteristics of ground clay bricks cement pastes. Beni-Suef University Journal of Basic and Applied Sciences 2: 20-30.

[8] C. Marthong and T. P. Agarwal (2012). Effect of Fly Ash additive on concrete properties. IJERA vol. 2, Issue4: 1986-1991.

[9] Isa Yuksel, Turhan Bilir and Omer Ozkan (2006). Durability of concrete incorporating non-ground blast furnace slag and bottom ash as fine aggregate. Building and environment 42: 2651-2659. 
[10] Association, T. B. (n.d.). Technical notes on Brick Constructions. Retrieved September 25, 2014, from http://www.gobrick.com:

http://www.gobrick.com/portals/25/docs/technical $\% 20$ notes/tn8b.pdf

[11] ACI 530/ASCE 5/TMS 402.Building Code Requirements for Masonry Structures.

[12] ASTM C 270, Standard Specification for Mortar for Unit Masonry, ASTM International.

[13] Standard Specification for Mortar for Unit Masonry, Annual Book of Standards, Vol. 04.05, ASTM International, West Conshohocken, PA, 2006.

[14] IS 2250- 1981, Code of Practice for Preparation and Use of Masonry mortars, Indian Standard.

[15] ISO 14688-1:2002, Geotechnical investigation and testing - Identification and classification of soil -Part 1: Identification and description

[16] ASTM D 98-98, Standard Specification for Calcium Chloride, ASTM International.

[17] IS 9103:1999, Specification for Concrete Admixtures, Indian Standard.

[18] IS 12269:1987, Specification for 53 Grade Portland cement, Indian Standard.

[19] IS 650-1991, Specification for Standard Sand for Testing of Cement, Indian Standard.

[20] IS 2386-1 (1963), Methods of Test for Aggregates for Concrete, Part I: Particle Size and Shape, Indian Standard.

[21] IS 383:1970, Specification for Coarse and Fine Aggregates, Indian Standard.

[22] IS 4031-11 (1988), Methods of physical tests for hydraulic cement, Part 11: Determination of density, Indian Standard.

[23] IS: 4031 (Part 4) - 1988, Methods of physical tests for hydraulic cement, Part 4: Determination of consistency of standard cement paste, Indian Standard.

[24] IS: 4031 (Part 5) - 1988, Methods of physical tests for hydraulic cement, Part 5: Determination of initial and final setting times, Indian Standard.

[25] M.S., S. (2012). Concrete Technology Theory and Practice. New Delhi: S.Chand and Company Ltd.

[26] J.J., N. A. (2012). Concrete Technology. New Delhi: Sanat Printers.

\section{BIOGRAPHIES}

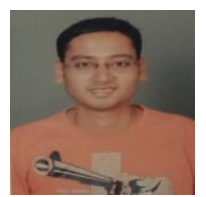

Sunil N Manjunath, Has completed civil engineering in GIT, Belgaum under VTU in the year 2013. Currently pursuing M.Tech in Structures at MIT, Manipal.

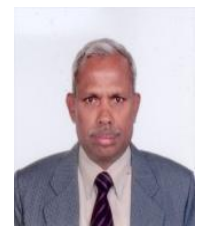

P V Sivapullaiah, Working as a Professor and has been Teaching at Indian Institute of Science, Bangalore, for over 3 decades. He has published more than 220 papers in International and National Journals and conference / seminar Proceedings.
M Prasanna Kumar, Has completed M.Tech in structures at MIT, Manipal in the year 2012. Currently working as Asst. Professor and also pursuing PHD at MIT, Manipal. 